\title{
Transporte de frangos: caracterização do microclima na carga durante o inverno ${ }^{1}$
}

\section{José Antonio Delfino Barbosa Filho ${ }^{2}$, Frederico Márcio Corrêa Vieira ${ }^{2}$, Iran José Oliveira da Silva ${ }^{3}$, Danilo de Brito Garcia ${ }^{4}$, Marco Aurélio Neves da Silva ${ }^{2}$, Bruno Henrique Fernandes Fonseca ${ }^{5}$}

\author{
1 Projeto financiado pela FAPESP. \\ 2 NUPEA/ESALQ/USP. \\ ${ }^{3}$ Departamento de Engenharia Rural - NUPEA/ESALQ/USP. \\ ${ }^{4}$ Estagiário - NUPEA/ESALQ/USP. \\ ${ }^{5}$ Departamento de Ciências Exatas - ESALQ/USP.
}

RESUMO - Este trabalho foi conduzido com o objetivo de caracterizar o perfil microclimático da carga de caminhões de transporte de frangos de corte sob condições comerciais durante o inverno, por meio do monitoramento constante das variáveis ambientais (temperatura e umidade relativa do ar) e das perdas na chegada na linha de abate. Foram monitorados três carregamentos, da saída das aves da granja até a chegada ao abatedouro, considerando fatores como a distância (perto, média e longa) e os turnos (manhã, tarde e noite). Para obtenção do perfil das variáveis ambientais durante a carga dos caminhões, foram instaladas miniestações meteorológicas (Loggers) que permitiram determinar o microclima a que as aves foram submetidas e visualizar o perfil do índice entalpia de conforto, que possibilitou a classificação das regiões da carga de acordo com os limites de conforto térmico para frangos de corte na sexta semana. Os dados de temperatura, umidade relativa do ar e do índice entalpia de conforto na carga foram analisados utilizando-se a geoestatística pelo método de krigagem ordinária. O turno da tarde foi o mais crítico do ponto de vista ambiental, e as partes central e traseira da carga do caminhão foram as mais problemáticas para as aves, do ponto de vista microclimático, portanto, as mais propícias à ocorrência de perdas.

Palavras-chave: avicultura, bem-estar animal, operações pré-abate

\section{Poultry transport: microclimate characterization of the truck during the winter}

\begin{abstract}
The objective of this study was to characterize the the microclimatic profile of broiler chicken transport trucks under commercial conditions, in the winter by continuous monitoring of environmental variables (temperature and relative air humidity) and deaths on arrival (DOA's). Three loads were monitored, from farm to slaughterhouse, considering factors such as distance (short, medium and long) and periods of the day (morning, afternoon and night). To obtain the environmental variables profile in the trucks during the journey, data loggers were installed in the trucks that determined the microclimate to which the birds were submitted and allowed the visualization of the Enthalpy Comfort Index (ECI) so that the lorry regions could be classified according to heat comfort limits for six-week old poultry. The temperature, relative humidity and ECI in the truck were analyzed using geostatistics, by the ordinary kriging method. The afternoon was the most critical period from the environmental point of view, and the central and rear parts of the truck were most problematic for the chickens from the microclimatic point of view and were thus the most susceptible to losses.
\end{abstract}

Key Words: animal welfare, poultry production, preslaughter operations

\section{Introdução}

A operação pré-abate no transporte das aves consiste na condução dos animais da granja até o abatedouro nas mais diferentes condições e combinações de distâncias e horários. Essas combinações refletem diretamente na qualidade do produto final (carne) e na maioria das vezes são os principais responsáveis pelas perdas (mortes).
Durante o transporte, as aves são submetidas a fatores estressantes que comprometem o bem-estar e causam prejuízos, em decorrência da elevada mortalidade e da queda na qualidade da carne (Mitchell et al., 1992; Mitchell \& Kettlewell, 1998).

Os principais fatores estressantes durante o transporte das aves estão relacionados ao microclima na carga, e os elevados valores de temperatura e umidade relativa do ar 
durante o transporte são os maiores responsáveis pelas chamadas “mortes na chegada” ou Dead on Arrivals (Hunter et al., 1997; Mitchell \& Kettlewell, 1998). Estudos conduzidos na Europa indicam que $40 \%$ das mortes na chegada são ocasionadas pelo transporte das aves até o abatedouro (Bayliss \& Hinton, 1990).

Sabe-se que a distribuição das aves mortas ao longo da carga não é aleatória; pelo contrário, reflete a variação da ventilação e das regiões de conforto. Kettewell \& Mitchell (1993) realizaram uma caracterização tridimensional das condições ambientais no interior da carga de caminhões comerciais de transporte de frangos e constataram grande heterogeneidade das variáveis ambientais dentro das cargas.

A produção de calor metabólico pelas aves durante o transporte cria gradientes térmicos entre as caixas de transporte e o meio externo, que será afetado também pela ação do vento em cada ponto, o que, por sua vez, resulta em distribuição heterogênea da temperatura ao longo da carga do caminhão (Mitchell \& Kettlewell, 1994). Resultados de pesquisas (Mitchell et al., 1992; Kettlewell \& Mitchell, 1993; Kettlewell et al., 1993) indicam a existência de um núcleo térmico na carga dos caminhões, originado pela baixa ventilação e em locais onde a carga térmica e a umidade são maiores. Todavia, esses estudos foram feitos em regiões de clima temperado e são escassas as pesquisas que evidenciam o perfil térmico da carga em condições climáticas tropicais, principalmente quando consideradas intensas flutuações térmicas diárias nas estações do ano.

Assim, este trabalho foi conduzido com o objetivo de caracterizar o perfil microclimático na carga de caminhões de transporte de frangos de corte durante o inverno e relacionar essas informações com as perdas durante esta operação pré-abate.

\section{Material e Métodos}

O experimento foi realizado em uma empresa integradora e um abatedouro localizado no interior do estado de São Paulo, com média de 300 mil aves abatidas diariamente. De acordo com os dados da estação meteorológica daquela localidade, a região está a uma altitude média de $800 \mathrm{~m}$, com clima tropical de altitude, com inverno seco e verão quente e úmido; a temperatura média nos meses mais frios pode ficar abaixo dos $18{ }^{\circ} \mathrm{C}$ e a umidade relativa média mensal varia de 53 a $89 \%$.

O período experimental foi de um mês, durante o inverno. As aves utilizadas no experimento foram da linhagem Cobb, com 6 a 7 semanas de idade. Foram monitorados três carregamentos, da saída das aves da granja até a chegada ao abatedouro, considerando fatores como a distância e os turnos de viagem.

Avaliaram-se três turnos de transporte (manhã, das $7 \mathrm{~h}$ às $11 \mathrm{~h} 59$; tarde, das $12 \mathrm{~h}$ às $17 \mathrm{~h} 59$; e noite, das $18 \mathrm{~h}$ às 6h59) e três distâncias (próxima, menos de $30 \mathrm{~km}$ da granja ao abatedouro; média, de 31 a 69 km da granja ao abatedouro; longa, mais de $70 \mathrm{~km}$ da granja ao abatedouro).

O transporte das aves foi realizado da seguinte forma: todos os caminhões monitorados tinham carga de 486 caixas de transporte dispostas em três fileiras (duas laterais e uma central), compostas de 9 caixas de altura e 18 caixas de comprimento.

Para obtenção do perfil das variáveis ambientais ao longo da carga dos caminhões, foram instaladas miniestações meteorológicas (Loggers) da marca Logen em toda a extensão, o que permitiu determinar o microclima ao qual as aves foram submetidas, bem como visualizar o perfil do índice entalpia de conforto (IEC), que possibilitou a classificação das regiões da carga de acordo com os limites de conforto térmico para frangos de corte na sexta semana. A entalpia (h) é um índice de conforto térmico que expressa a quantidade de calor, em kcal, em $1 \mathrm{~kg}$ de ar seco, determinada pela equação empírica (1) (Barbosa Filho, 2008):

$$
\mathrm{h}=6,7+0,243 \times \mathrm{Tbs}+\left\{\frac{\mathrm{UR}}{100} \times 10^{\frac{7,5 \times \mathrm{Tbs}}{237,3+\mathrm{Tbs}}}\right\}
$$

em que: $\mathrm{h}$ = entalpia (kcal/kg ar seco); Tbs = temperatura do bulbo seco $\left({ }^{\circ} \mathrm{C}\right)$; UR = umidade relativa (\%).

Para facilitar a distribuição das miniestações meteorológicas e abranger toda a extensão da carga, optou-se por uma configuração fixa e padrão em todos os carregamentos (Figura 1).

Para os três carregamentos avaliados, foram monitorados os perfis de temperatura e umidade relativa do ar no interior e exterior da carga do caminhão, bem como as características particulares de cada viagem, como a distância percorrida, o turno de transporte, o tempo de viagem, a densidade de aves por caixa e a porcentagem de mortes na chegada.

Essa configuração de distribuição contou com 47 miniestações meteorológicas, dispostas em maior quantidade no centro da carga, por presumir que essa seria a região mais propensa à ocorrência de estresse térmico nas aves.

Os dados de temperatura, umidade relativa do ar e do índice entalpia de conforto ao longo da carga foram analisados utilizando-se a geoestatística (krigagem ordinária) para a obtenção dos demais pontos da carga e avaliação da dependência espacial das variáveis ambientais, 

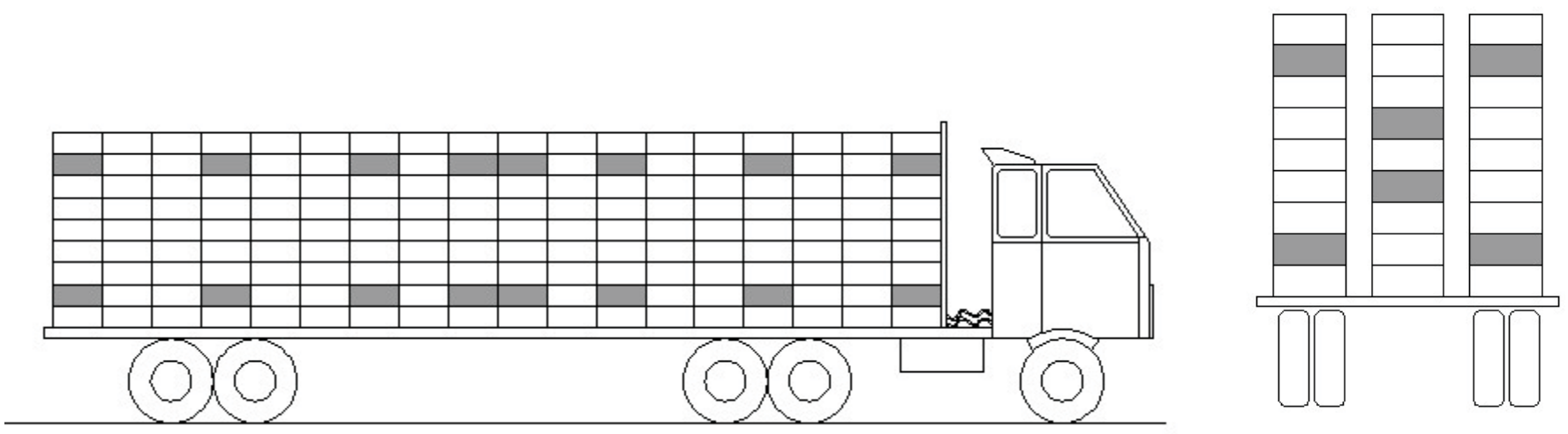

Figura 1 - Distribuição das miniestações meteorológicas (caixas escuras) ao longo da carga.

conside-rando como área de estudo o interior da carga do caminhão. Em cada conjunto de dados, as amostras foram divididas em três grupos, L1 - lateral 1, M - meio e L2 Lateral 2.

Em todas as etapas dessa análise, foi utilizado o software estatístico R (R Development Core Team, 2006).

\section{Resultados e Discussão}

A distância do percurso granja-abatedouro pode ser classificada, para os turnos da manhã, tarde e noite, como próxima (até $30 \mathrm{~km}$ ) (Tabela 1). Os tempos de transporte acompanharam as mesmas variações das distâncias, uma vez que maior tempo foi observado no turno da noite (dia 3).

A informação apresentada pela coluna aves por caixa (aves/caixa) indica pouca variação da densidade de aves por caixa nos dias avaliados, no entanto, para o turno da manhã, que apresenta melhores condições ambientais, essa densidade pode ser um pouco maior que nos outros turnos e isso não acarreta aumento da porcentagem de perdas (\%Morte).

As condições ambientais externas acompanharam as oscilações normais dos turnos do dia para o inverno na região onde foi conduzido o experimento. A média de temperatura foi em torno de $21^{\circ} \mathrm{C}$ e a umidade relativa de $63 \%$.

A porcentagem de mortes na chegada (\%Morte) indica inicialmente o esperado, ou seja, que as maiores perdas ocorressem de fato durante o turno da tarde, período de maior evidência de estresse térmico (Warriss et al., 2005). No entanto, o turno da noite apresenta porcentagem de mortes próximo ao do turno da tarde, o que, neste caso, pode indicar inversão da condição de estresse térmico por calor para uma situação de estresse térmico por frio (Mitchell et al., 2001; Hunter et al., 1999).

As médias gerais das variáveis ambientais das três expedições de transporte monitoradas durante o inverno (Tabela 2) foram obtidas tomando-se as médias das 47 miniestações espalhadas ao longo do perfil da carga, que sumarizam em um único valor as condições ambientais da carga no momento do transporte, além de servirem como parâmetro de comparação entre os turnos.

Considerando o calor presente na carga (IECCarga) dos caminhões durante os transportes (Tabela 2), conforme a classificação das tabelas de entalpia (Barbosa Filho et al., 2007), os turnos da manhã e noite são os mais indicados para o transporte das aves. No entanto, a classificação do

Tabela 1 - Médias das variáveis ambientais externas para cada turno de transporte das aves

\begin{tabular}{lccccccrc}
\hline Estação & Dia & Turno & Distância $(\mathrm{km})$ & Tempo & Aves/caixa & $\begin{array}{c}\text { Temperatura } \\
\text { externa }\left({ }^{\circ} \mathrm{C}\right)\end{array}$ & $\begin{array}{c}\text { Umidade relativa } \\
\text { externa }(\%)\end{array}$ \\
\hline Inverno & 1 & Manhã & 15 & $0: 15$ & 9 & 20,0 & 66 & $\begin{array}{c}\text { \%Morte } \\
\end{array}$ \\
& 2 & Tarde & 20 & $0: 20$ & 7 & 24,2 & 55 & 0,10 \\
& 3 & Noite & 30 & $0: 40$ & 7 & 21,0 & 69 \\
\hline
\end{tabular}

Tabela 2 - Médias das variáveis ambientais na carga em cada turno de transporte das aves

\begin{tabular}{lccccccc}
\hline Estação & Dia & Turno & Temperatura da carga $\left({ }^{\circ} \mathrm{C}\right)$ & Umidade relativa da carga (\%) & IEC carga $(\mathrm{kJ} / \mathrm{kg}$ ar) & \%Morte & Molha \\
\hline Inverno & 1 & Manhã & 22,4 & 67 & 63,2 & 0,10 & Não \\
& 2 & Tarde & 25,2 & 89 & 73,1 & 0,35 & Sim \\
& 3 & Noite & 22,8 & 78 & 66,0 & 0,28 & Sim \\
\hline
\end{tabular}


índice entalpia de conforto para os turnos da manhã e noite não dispensa qualquer atenção quanto aos fatores térmicos; é indicado o controle constante da temperatura e umidade relativa no ambiente onde são realizadas as operações.

É importante também a análise da eficiência da prática do molhamento (molha) na redução da quantidade de calor na carga. Os valores de umidade relativa da carga alteraram de acordo com o molhamento, passando de valores em torno de $60 \%$ para valores superiores a $75 \%$ (Tabela 2), o que reduziu a carga térmica sobre as aves. No entanto, valores muito elevados de umidade relativa podem também afetar o sistema de trocas térmicas das aves, comprometendo as condições de conforto térmico e bem-estar, principalmente no inverno, caracterizado pela temperatura e umidade relativa baixa, resultando no estresse por frio (hipotermia), uma vez que o molhamento muitas vezes é feito sem critérios.

As amplitudes dos valores de temperatura foram de 1,7 a $7,5{ }^{\circ} \mathrm{C}$ e as maiores diferenças ocorreram nos valores encontrados para os turnos da tarde e noite em comparação aos da manhã (Tabela 3).

A amplitude dos valores de umidade relativa do ar foi influenciada pela prática do molhamento da carga e apresentou pequena variação entre as partes da carga (L1, M e L2) para o turno da manhã em relação aos turnos da tarde e noite em que ocorreu o molhamento da carga. A desuniformidade no molhamento entre as partes da carga evidencia alterações nas amplitudes de umidade nos turnos da tarde e noite e as laterais (L1 e L2) foram mais molhadas que a parte central (M).

As amplitudes do índice entalpia de conforto (IEC) apresentaram diferença entre os turnos da manhã e noite em relação ao da tarde, principalmente na parte central (M) e na lateral 2 (L2) da carga (Figura 2), o que indica que as variações nos valores de temperatura e umidade relativa na carga, provocadas pelo molhamento, influenciaram a amplitude dos valores do índice entalpia de conforto.
É possível notar grande diferença nos valores do índice entalpia de conforto para os três turnos avaliados (Figura 2). Durante o turno da manhã, observa-se uma grande região de conforto térmico ao longo do perfil da carga, que é o melhor turno para o transporte das aves, pois oferece condições ambientais mais propícias para esta operação pré-abate.

O turno da tarde apresenta perfil inadequado ao conforto térmico para frangos de corte na sexta semana de vida, que variam de 54,7 a $62,9 \mathrm{KJ} / \mathrm{kg}$ de ar seco (Barbosa Filho et al, 2007). A região de pior condição microclimática situa-se nas partes central e traseira da
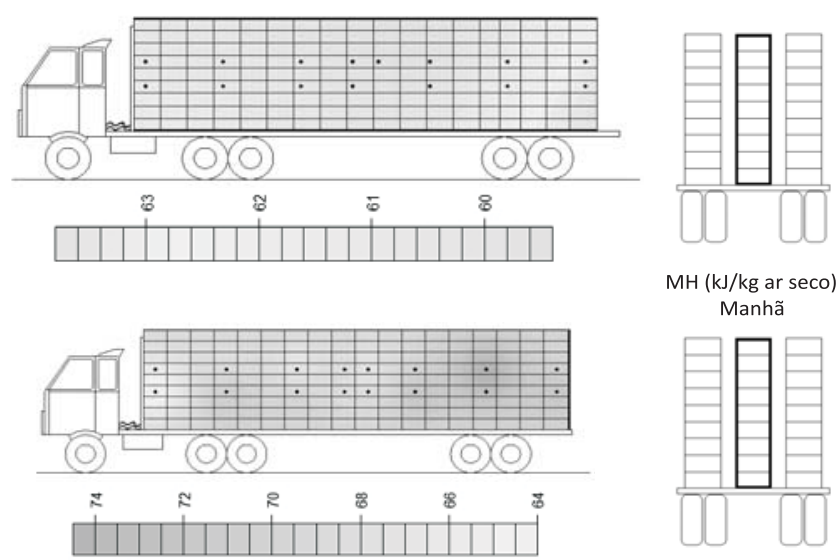
Manhã
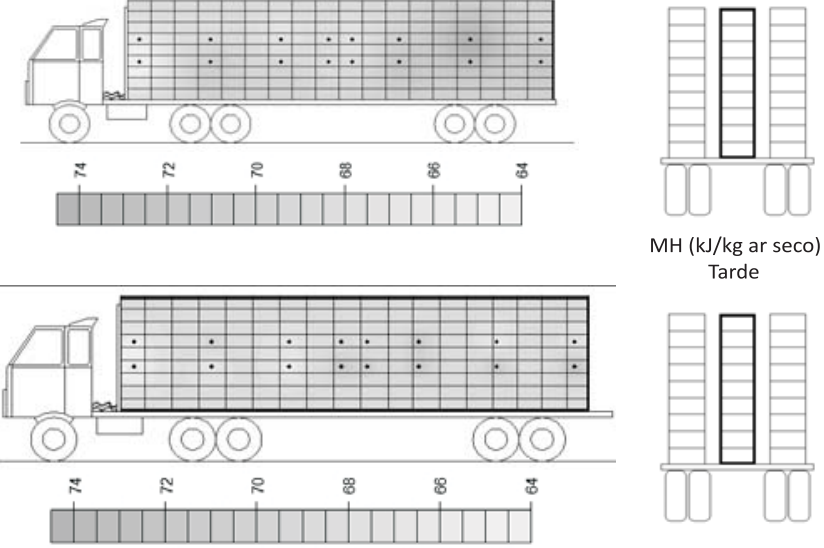
Tarde

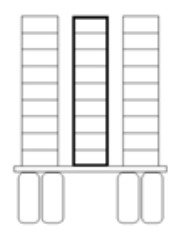

$\mathrm{MH}(\mathrm{kJ} / \mathrm{kg}$ ar seco) Noite

Figura 2 - Perfil térmico do índice entalpia de conforto ao longo da fileira do meio da carga para os três carregamentos avaliados e seus respectivos turnos.

Tabela 3 - Amplitudes das variáveis ambientais (temperatura e umidade relativa) e do índice entalpia de conforto para cada parte da carga (L1, M e L2) em cada turno de transporte

\begin{tabular}{|c|c|c|c|c|c|c|c|}
\hline \multirow[b]{2}{*}{ Estação } & \multirow[b]{2}{*}{ Dia } & \multirow[b]{2}{*}{ Turno } & \multirow[b]{2}{*}{ Molha } & \multicolumn{3}{|c|}{ Amplitude } & \multirow[b]{2}{*}{ Variável } \\
\hline & & & & L 1 & M & $\mathrm{L} 2$ & \\
\hline \multirow[t]{9}{*}{ Inverno } & 1 & Manhã & Não & 2,0 & 3,5 & 4,4 & Temperatura \\
\hline & 2 & Tarde & Sim & 7,0 & 4,0 & 2,7 & \\
\hline & 3 & Noite & Sim & 1,7 & 7,5 & 6,5 & \\
\hline & 1 & Manhã & Não & 12,0 & 16,0 & 14,0 & Umidade relativa \\
\hline & 2 & Tarde & Sim & 28,0 & 16,0 & 17,0 & \\
\hline & 3 & Noite & Sim & 12,0 & 8,0 & 25,0 & \\
\hline & 1 & Manhã & Não & 7,5 & 4,4 & 4,0 & Índice entalpia de conforto \\
\hline & 2 & Tarde & Sim & 5,0 & 10,5 & 9,5 & \\
\hline & 3 & Noite & Sim & & 10,0 & 9,0 & \\
\hline
\end{tabular}


carga, o que as coloca como localidades mais suscetíveis à ocorrência de perdas durante o transporte das aves.

No turno da noite, a variação do índice entalpia de conforto é semelhante à do turno da tarde, com valores elevados, o que permite classificar quase todas as regiões da carga em situação de alerta às condições de conforto térmico para aves na sexta semana. O que diferencia o perfil do turno da noite com o da tarde é a influência da prática do molhamento da carga neste último turno. Esse molhamento contribuiu para a elevação dos valores de umidade relativa do ar no interior da carga, o que, por sua vez, alterou os valores do índice entalpia de conforto, mesmo com a temperatura dentro dos limites de conforto térmico para frangos na sexta semana (Macari \& Furlan, 2001).

As regiões traseira e central da carga foram as de piores condições microclimáticas para as aves (Tabela 4). Durante o inverno, o turno da tarde caracterizou-se como possível causador de perdas durante as operações pré-abate das aves, portanto, é recomendável evitar transportar as aves nos turnos de temperaturas mais elevadas.

A maioria das aves que chegaram mortas no abatedouro estava localizada nas regiões central e traseira da carga, consideradas de condições microclimáticas inadequadas ao conforto térmico das aves (Hunter et al., 1997).

Tabela 4 - Regiões de pior microclima ao longo da carga em turno de transporte das aves

\begin{tabular}{|c|c|c|c|c|c|c|}
\hline \multirow[b]{2}{*}{ Estação } & \multirow[b]{2}{*}{ Dia } & \multirow[b]{2}{*}{ Turno } & \multirow[b]{2}{*}{ Molha } & \multicolumn{3}{|c|}{ Regiões de pior microclima } \\
\hline & & & & L 1 & M & L 2 \\
\hline \multirow[t]{2}{*}{ Inverno } & 1 & Manhã & Não & Traseira & Traseira & Central \\
\hline & 3 & Noite & Sim & Traseira & Toda & Central \\
\hline
\end{tabular}

\section{Conclusões}

No inverno, para a operação pré-abate de transporte das aves, o turno da tarde é o mais suscetível à ocorrência de perdas por estresse térmico.

\section{Literatura Citada}

BARBOSA FILHO, J.A.D. Caracterização quantiqualitativa das condições bioclimáticas e produtivas nas operações pré-abate de frangos de corte. 2008. 174f. Tese (Doutorado em Física do Ambiente Agrícola) - Escola Superior de Agricultura “Luiz de Queiroz”/Universidade de São Paulo, Piracicaba, 2008.

BARBOSA FILHO, J.A.D.; VIEIRA, F.M.C.; GARCIA, D.B. et al. [2007]. Mudanças e uso das tabelas de entalpia. Piracicaba, 2007. Disponível em: <http://www.nupea.esalq.usp.br>. Acesso em: $15 / 1 / 2008$.

BAYLISS, P.A.; HINTON, M.H. Transportation of broilers with special reference to mortality rates. Applied Animal Behaviour Science, v.28, p.93-118, 1990.

HUNTER, R.R.; MITCHELL, M.A.; MATHEU, C. Distribution of "Dead on Arrivals" within the bio-load on commercial broiler transporters: correlation with climatic conditions and ventilation regimen. British Poultry Science, v.38, p.7-9, 1997.

HUNTER, R.R.; MITCHELL, M.A.; CARLISLE, A.J. Wetting of broilers during cold weather transport: a major source of physiological stress? British Poultry Science, v.40, p.48-49, 1999.
KETTLEWELL, P.J.; MITCHELL, M.A. The thermal environment on poultry transport vehicles. COLLINS, E. ;BOON, C. (Eds.) In: INTERNATIONAL SYMPOSIUM, 4., 1993, St. Joseph. Proceedings... St. Joseph: American Society of Agricultural Engineers, 1993. p.345-389.

KETTLEWELL, P.J.; MITCHELL, M.A.; MEEHAN, A. The distribution of thermal loads within poultry transport vehicles. Agricultural Engineer, v.48, p.26-30, 1993.

MACARI, M.; FURLAN, R.L. Ambiência na produção de aves em clima tropical. In: SILVA, I.J. (Ed.) Ambiência na produção de aves em clima tropical. Piracicaba: FUNEP, 2001. p.31-87.

MiTCHELL, M.A.; KETTLEWELL, P.J.; MAXWELL M.H. Indicators of physiological stress in broiler chickens during road transportation. Animal Welfare, v.1, p.91-103, 1992.

MITCHELL, M.A.; KETTLEWELL, P.J. Road transportation of broiler-chickens - induction of physiological stress. World's Poultry Science Journal, v.50, p.57-59, 1994.

MITCHELL, M.A.; KETTLEWELL, P.J. Physiological stress and welfare of broiler chickens in transit: solutions not problems! Poultry Science, v.77, p.1803-1814, 1998.

MitCHELL, M.A.; KETTLEWELL, P.J.; HUNTER, R.R. et al. Physiological stress response modeling - application to the broiler transport thermal environment. In: INTERNATIONAL SYMPOSIUM, 6., 2001, Louisville. Proceedings... Louisville: 2001. p.550-555. (Livestock Environment, 6).

R DEVELOPMENT CORE TEAM. R: a language and environment for statistical computing. Vienna: R Foundation for Statistical Computing, 2006. (CD-ROM).

WARRISS, P.D.; PAGAZAURTUNDA, A.; BROWN, S.N. Relationship between maximum daily temperature and mortatily of broiler chickens during transport e lairage. British Poultry Science, v.46, p.647-651, 2005. 